\title{
Relative probability, interstimulus interval, and speed of the same-different judgment '
}

\author{
SHIZUHIKO NISHISATO AND JACK S. WISE
}

MCGILL UNIVERSITY

Pairs of tones were judged to be "same" or "different" by four well-practiced Ss. The speed of these judgments, measured as reaction time (RT), was studied as a function of the relative probability of "same" trials and the interstimulus interval. Three levels of probability $(.75, .50$, and .25 ) and three interstimulus intervals (1 sec., $0.5 \mathrm{sec}$, and simultaneous presentation) were used. A four-way analysis of variance showed the judgment "same" to have longer RT than the judgment "different," and the middle interval $(0.5$ sec.) to have a shorter reaction time than either of the other intervals. Probability did not show any significant main effect; possible reasons for this are discussed.

Previous studies have shown that in a disjunctive reaction time (DRT) task the relative probability of presentation of each stimulus affects reaction time (RT); the more frequent of the two stimuli yields the shorter RT (e.g., Hyman, 1953; LaBerge \& Tweedy, 1964). It has also been shown in a successive discrimination task that the interval between the two test stimuli has a significant effect on reaction speed (e.g., Creamer, 1963). As a special case of the DRT task, one can ask Ss whether a comparison stimulus is the same as, or different from, a standard stimulus, and require them to indicate the "same" or "different" judgment by pressing one of two keys as quickly as possible (Bindra, Williams, \& Wise, 1965). The present experiment was conducted to see whether the relative probability of "same" and "different" trials and the interstimulus interval would affect the speed of the same-different judgment. We employed a design in which the effects of three variables, relative probability of "same" trials, interstimulus interval, and "same" vs. "different" judgment, as well as their interactions, could be studied.

\section{Method}

The Ss were four well-practiced university students. Their ages ranged from 21 to 24 years.

Two 4-sec., 66-dB tones, A (1000 cps) and B (1060 cps), were presented to $S$ successively or simultaneously through earphones. Each pair of the tones (AA, $\mathrm{AB}, \mathrm{BA}$, and $\mathrm{BB}$ ) was judged as "same" or "different" with respect to pitch by Ss. On each trial a "ready" signal (illumination for 1 sec. of a red 7.5-w lamp) was followed after an interval of 1 sec. by one of the four classes of tone pairs. $S$ was required to press a response key, labeled "Same," if he thought the two tones were identical, and to press the other response key, labeled "Different," if he thought the two tones were dissimilar. The interstimulus interval in suc- cessive presentation was either $1 \mathrm{sec}$. or $0.5 \mathrm{sec}$. All Ss were tested on three 32-trial blocks per day, each block was preceded by a few practice trials. The blocks differed in that the relative probability of the "same" trials (AA or BB) in a block was either .75 or .50 , or .25 . The interstimulus interval remained constant from block to block, but was changed from day to day. The order of presentation of each "probability block" within daily sessions, as well as the order of presentation of the different interstimulus intervals across days, was different for each $\mathrm{S}$. Both speed and accuracy of response were emphasized in instructions to Ss. The experiment was completed in three sessions, one per day.

$S$ rested the index finger of his preferred hand at a point equidistant from the two response keys. The labels "Same" and "Different" were interchanged between $\mathrm{Ss}$ in order to balance the effects attributable to any special characteristics of the keys or of direction of movement. The interval between the onset of the second tone and the reaction (the pressing of a response key) in the case of successive presentation, or the interval between the onset of both tones and the reaction in the case of simultaneous presentation was recorded on each trial on a millisecond timer. A response lamp indicated to the experimenter which key was pressed by $\mathrm{S}$.

Results

About $20 \%$ of the responses were errors. A Friedman two-way analysis of variance by ranks revealed that the number of errors obtained under each of the three different probabilities did not differ significantly, but the same test showed that error rate was affected by the interstimulus interval $\left(x^{2}=7.00, \mathrm{df}=2, \mathrm{p}<.05\right)$. Most errors were made under the simultaneous presentation condition; the number of errors recorded under the two successive presentation conditions did not differ significantly.

A four-way analysis of variance (judgment of same or different by interstimulus interval by probability by subjects), based on each S's means, revealed that Ss tended to take longer to reach the decision "same" than to reach the decision "different" (judgment effect, $\mathrm{F}=15.39, \mathrm{df}=1 / 3, \mathrm{p}<.05)$. Moreover, Ss had the longest RT when the test stimuli were presented simultaneously, and had the shortest RT when the interstimulus interval was $0.5 \mathrm{sec}$. (interval effect, $\mathrm{F}=\mathbf{1 5 . 0 7}$, $\mathrm{df}=$ $2 / 6, p<.01)$. The probability factor did not show any significant effect. RT among Ss differed significantly (subject effect, $\mathrm{F}=3072.66, \mathrm{df}=3 / 12, \mathrm{p}<.01$ ). 
Table 1. Mean Reaction Times (msec.) for "Same" (S) and "Different" (D) Judgments obtained from Four Ss under Three Levels of Probability and Three Interstimulus Intervals

\begin{tabular}{lrrrrrrr}
\multicolumn{8}{c}{ Probability of "Same" } \\
$\begin{array}{l}\text { Interstimulus } \\
\text { Interval in sec. }\end{array}$ & \multicolumn{1}{c}{.75} & & D & S & D & S & D \\
\hline 0.0 & 1034 & 1046 & 1004 & 956 & 1034 & 984 \\
0.5 & 566 & 532 & 628 & 566 & 558 & 563 \\
1.0 & 633 & 548 & 667 & 601 & 598 & 579 \\
\hline
\end{tabular}

Although the probability main effect was not significant, each $\mathrm{S}$ responded to changes in the probability in a self-consistent, idiosyncratic way (probabilitySs interaction, $F=10.70, \mathrm{df}=6 / 12, \mathrm{p}<.01$ ). Again, the degree to which changes in the way of stimulus presentation, successive or simultaneous, affected each S's RT differed significantly (interval-Ss interaction, $F=$ 189.08, $\mathrm{df}=6 / 12, \mathrm{p}<.01$ ). It was further noted that, although all Ss took longer to reach the decision "same" the extent to which they did this differed significantly (judgment-Ss interaction, $F=4.94$, $\mathrm{df}=$ $3 / 12, p<.05)$. The mean RTs with Ss pooled are presented in Table 1.

Since the probability variable did not show a significant main effect, the RTs on the last 16 trials of each 32-trial block, which were expected to be more likely to reveal a probability effect, were analyzed. The result, however, failed to reveal any significant effect. Discussion

The present study confirms the finding by Bindra, Williams, \& Wise (1965) that the judgment "same" takes longer to arrive at than the judgment "different" when tones, successively presented, are judged. It also shows that this relation between the same and different judgments holds under the simultaneous pre- sentation condition, especially when the relative probability of the "same" and "different" trials is the same (see Table 1). Moreover, the interstimulus interval is shown to play a significant role in the samedifferent judgment. The effect of the probability, however, did not attain the significance level. This failure of the relative probability variable to have a significant effect could have resulted from the schedule of the present experiment, that is, from the use of different relative probabilities in three blocks within one daily experimental session. It may be that, had the experimental schedule involved using the same probability value in all the blocks of a session, a relative probability effect might have appeared. Ss may require more than 32 trials to learn that a discrepancy exists between the relative probability of different types of trials. The fact that the subject variable showed significant interactions with other factors, as well as a significant main effect, indicates the importance of individual differences in attitudes or strategies adopted.

\section{References}

Bindra, D., Williams, Judith A., \& Wise, J. S. Judgments of sameness and difference: Experiments on decision time. Science, $1965,150,1625-1627$.

Creamer, L. R. Event uncertainty, psychological refractory period, and human data processing. J. exp. Psychol., 1963, 66, 187194.

Hyman, R. Stimulus information as a determinant of reaction time. J. exp. Psychol., 1953, 45, 188-196.

LaBerge, D., \& Tweedy, J. R. Presentation probability and choice time. J. exp. Psychol., 1964, 68, 477-481.

\section{Note}

1. This research was supported by a Contract (Nonr-4896(00)) between the United States Office of Naval Research and McGill University and by a research grant (9425-10) from the Defence Research Board of Canada to Dr. Dalbir Bindra. 